\title{
Elicitation of expert knowledge on dynamics of Salmonella infections and contamination in the pork chain
}

Van der Gaag, M.A. ${ }^{1.2}$, H.W. Saatkamp ${ }^{2}$, R.B.M. Huirne ${ }^{2}$

1) Research Institute for Animal Husbandry, Lelystad, The Netherlands

2) Wageningen University (Hollandseweg I, $6706 \mathrm{KN}$ Wageningen, phone: $(+31) 317484065$, fax: (+3) 317 482745, e-mail: Monique.vanderGaagâalg.abe.wau.nl)

Summary There is little information available from experiments and literature on the course of Salmonella infections in pigs and on the course of contamination at slaughter. To obtain such information, an expert elicitation study was carried out in the Netherlands ( 23 respondents). The estimation of the experts for the most likely duration to be infectious after infection with Salmonello is for a pig 38 days. The most likely duration to be a carrier was estimated at 55 days and to become serological negative 109 days. Application of fermented feed decreases the infectious period by 11 days. At slaughter, the average number of carcasses at risk after one to four contaminated carcasses was 10 to 21 . So the duration of infection can be shoriened by e.g. feed measures. In a situation that infected pigs enter the slaughterhouse, the order of the pigs to be slaughtered is important.

Keywords: survey, zoonosis, epidemiology, pigs, control

Introduction There is little information available from experiments and literature on the course of Salmonella infections in pigs and on the course of contamination at slaughter. For efficient control of Salmonella in the pork chain, insight in the dynamics of the infection in live pigs and of contamination at the slaughterhouse is essential. A survey was designed for experts in the Netherlands and Denmark in order to bring together their knowledge on these items.

Materials and Methods In total 75 experts were invited to participate in a survey, 45 Dutch experts during February and March 2001 and 30 Danish experts in June 2001. An expert was defined as someone who is related to the pork chain and who is known for his/her knowledge of Salmonella in pigs and/or pork. The survey focused on the best control strategy per stage and on eleven variables about introduction and spread of Salmonella in the chain. For each stage prevention and reduction measures were given and the experts divided 100 points to indicate the relative importance per measure. Seven variables regarding live pigs were the duration of the seroconversion period, of the infectious period (with or without fermented feed), of the carrier period, the period to return to the serologically negative status and the infection rate (for serological positive and negative pigs). 
The four variables regarding contamination of carcasses at slaughter were: number of carcasses at risk when one or four preceding carcasse(s) are contaminated, probability for infected pigs to end up contaminated and probability for free pigs to end up contaminated when $50 \%$ of the pigs slaughtered that day were infected. For each variable the expected minimum, most likely and maximum value was asked.

Results and discussion From the Dutch experts, 23 (51\%) completed the survey and at the time of this paper the Danish survey was not finished yet, so the following results are based on Dutch respondents only. The individual variance within the estimations of the variables among respondents is large. To prevent inordinate impact of extreme values, the highest and lowest value per variable are excluded from the database. According to respondents, a pig that becomes infected is serologically positive in 12 days ( $s d=3, n=11$ ). See Figure 1. The most likely duration of the infectious period after the pig is infected for the first time is 32 days $(s d=23, n=7)$ and for pigs fed with fermented feed this period is 21 days ( $s d=17$, $\mathrm{n}=7$ ). Pigs that were recovered and are infected for the second time, the expected infectious period is 30 days ( $s d=27, n=7$ ). After the infectious period the pig stops shedding but it still carries bacteria in the lymph nodes or intestines, the so-called carrier period. The most likely duration of this period is 58 days $(s d=21, n=7)$.

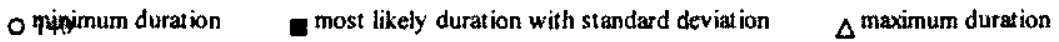

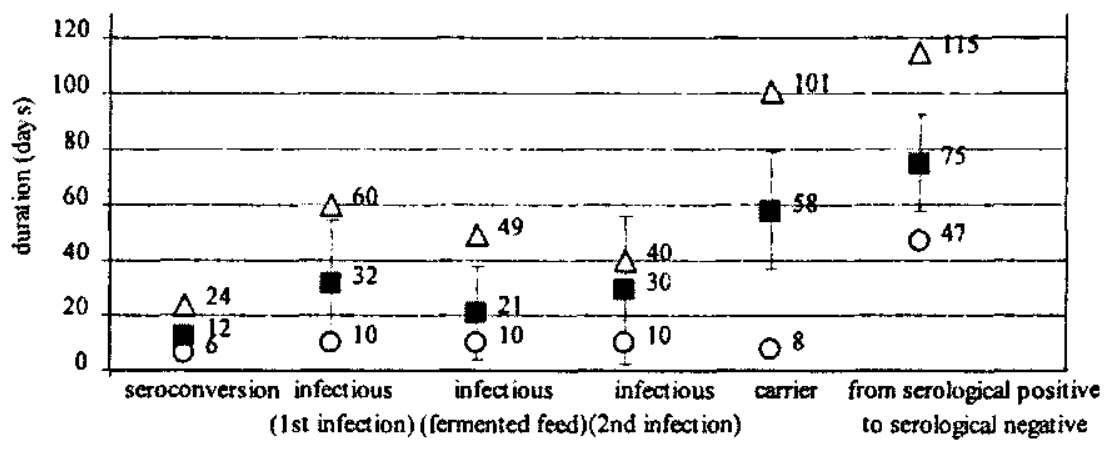

Figure 1 Minimum, most likely and maximum duration in days of six epidemiological states (values are average values of 7 to 11 respondents)

At slaughter the contamination of carcasses depends on the status of the animal before slaughter and of the status of the preceding carcasses. The most likely probability an infected pig ends up as a contaminated carcass when no other infected pigs are slaughtered is $37 \%$ (minimum probability is $11 \%$ and maximum is $68 \%$ ). The probability that a free pig ends up as a contaminated carcass when half of the slaughtered pigs are infected is $43 \%$ (minimum $21 \%$ and maximum $77 \%$ ). 
After one contaminated carcass at the slaughterline the 10 successive carcasses are at risk to get contaminated $(s d=8, n=7)$. With four contaminated carcasses in a row the respondents estimated that $21(\mathrm{sd}=17, \mathrm{n}=7)$ successive carcasses are at risk.

The three most preferable control measures per stage are shown in Table 1 (17 to 21 respondents per stage). Measures with respect to hygjene are preferable in all stages. For the primary stages application of fermented feed is also advisable. For the other stages logistic supply is useful according the respondents. This harmonises with the estimations of the variables of contamination in the slaughterhouse as mentioned above.

Table 1 Three most preferable measures per stage to minimise the Salmonella prevalence

\begin{tabular}{|c|c|c|c|c|c|}
\cline { 2 - 6 } & Multiply & Finish & Transport & Lairage & Slaughter \\
\hline $\begin{array}{c}\text { Salmonella free } \\
\text { feed }\end{array}$ & $\begin{array}{c}\text { Certified Salmonella } \\
\text { free piglets }\end{array}$ & $\begin{array}{c}\text { Hygiene to } \\
\text { prevent } \\
\text { introduction }\end{array}$ & $\begin{array}{c}\text { Logistic supply of } \\
\text { pigs }\end{array}$ & $\begin{array}{c}\text { Logistic } \\
\text { supply of pigs }\end{array}$ \\
\hline $\begin{array}{c}\text { Hygiene to } \\
\text { prevent spread }\end{array}$ & $\begin{array}{c}\text { Hygiene to prevent } \\
\text { introduction and } \\
\text { teduce spread }\end{array}$ & Logistic transport & $\begin{array}{c}\text { Hygiene to prevent } \\
\text { introduction }\end{array}$ & $\begin{array}{c}\text { Hygiene to } \\
\text { prevent spread }\end{array}$ \\
\hline 3 & $\begin{array}{c}\text { Fermented feed } \\
\text { for piglets }\end{array}$ & $\begin{array}{c}\text { Fermented feed for } \\
\text { pigs }\end{array}$ & $\begin{array}{c}\text { I compartment of } \\
\text { finishing farm/ ride }\end{array}$ & $\begin{array}{c}\text { Hygiene to prevent } \\
\text { spread }\end{array}$ & $\begin{array}{c}\text { Careful } \\
\text { evisceration }\end{array}$ \\
\hline
\end{tabular}

1) Hygiene to prevent introduction: measures such as sanitary lock, rodent control. 2) Hygiene to reduce spread: measures such as closed compartments, cleansing and disinfecting, smooth surfaces. 3) Logistic supply: order of supply is based on the prevalence in herd or group (lowest prevalence first).

Due to increasing food safety concerns most hygiene measures probably become regulation within several years. Although logistic transport and slaughter is expected to yield much improvement, more field experiments are necessary to justify such measures in practice.

Conclusions The best Salmonella control measures are improved hygiene and logistic operating procedures and in the primary stages also the application of fermented feed. The duration of states in the course of infection shows a lot of variation and most experts also expect large variation between individual pigs. Nevertheless the ranges given by the respondents give more insight in the course of infection in live pigs and of contamination at slaughter.

Acknowledgements Thanks to all respondents for their time and co-operation. 